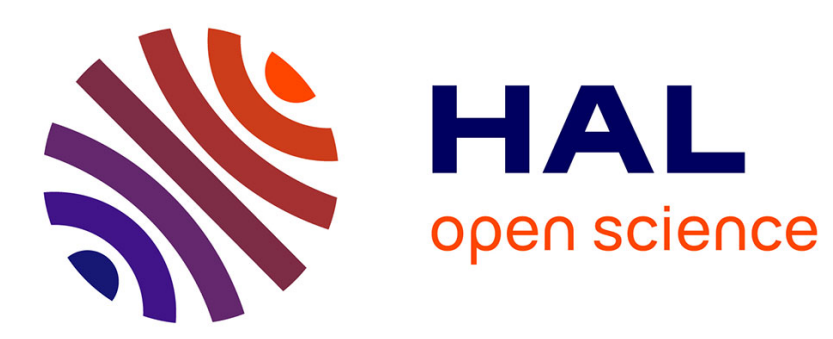

\title{
Magnetic Compensation Effect in TbFe1-xAlxO3 System
}

\author{
A. Bombik, B. Lesniewska, A. Pacyna
}

\section{To cite this version:}

A. Bombik, B. Lesniewska, A. Pacyna. Magnetic Compensation Effect in TbFe1-xAlxO3 System. Journal de Physique IV Proceedings, 1997, 07 (C1), pp.C1-373-C1-374. 10.1051/jp4:19971153 . jpa00254798

\section{HAL Id: jpa-00254798 https://hal.science/jpa-00254798}

Submitted on 1 Jan 1997

HAL is a multi-disciplinary open access archive for the deposit and dissemination of scientific research documents, whether they are published or not. The documents may come from teaching and research institutions in France or abroad, or from public or private research centers.
L'archive ouverte pluridisciplinaire HAL, est destinée au dépôt et à la diffusion de documents scientifiques de niveau recherche, publiés ou non, émanant des établissements d'enseignement et de recherche français ou étrangers, des laboratoires publics ou privés. 


\title{
Magnetic Compensation Effect in $\mathrm{TbFe}_{1-x} \mathrm{Al}_{x} \mathrm{O}_{3}$ System
}

\author{
A. Bombik, B. Leśniewska and A.W. Pacyna* \\ Faculty of Physics and Nuclear Techniques, University of Mining and Metallurgy, ul. Wkadyskawa \\ Reymonta 19, 30-059 Kraków, Poland \\ * The Henryk Niewodniczahski Institute of Nuclear Physics, ul. Walerego Eljasza Radzikowskiego 152, \\ 31-342 Kraków, Poland
}

\begin{abstract}
Magnetic susceptibility measurements for solid solutions of $\mathrm{TbFe}_{1-x} \mathrm{Al}_{x} \mathrm{O}_{3}$, in the whole range of $\mathrm{Al}$ concentration, have been carried out. The obtained results indicate an essential role of the Al substitute in the magnetic behaviour of examined compounds. The generation of compensation effect, which modifies the susceptibility of the system, seems to be of particular interest. The compensation temperatures have been determined from some singularities visible on susceptibility curves for compounds with Al concentration $0.06 \leq x \leq 0.70$.
\end{abstract}

\section{INTRODUCTION}

In solid solutions of orthoferrites - $\mathrm{REFe}_{1-x} \mathrm{Al}_{x} \mathrm{O}_{3}$ (where $\mathrm{RE}$ stands for a rare earth atom), the nonmagnetic substitute (AI) causes an essential modification in the magnetic properties the system. The $\mathrm{Al}$ and similar substitutes (Ga, In, Sc), acceptable in the 4(b) position of the orthoferrite structure (Pbnm), can be regarded as magnetic vacancies in the iron sublattice. Theoretical analysis showed that such vacancies strongly influence the magnetic-anisotropy energy of the $\mathrm{REFe}_{1-x} \mathrm{Al}_{x} \mathrm{O}_{3}$, and thus may change the sign of the RE-Fe interaction (from F to AF coupling) [1]. In orthoferrites, the antiferromagnetic RE-Fe coupling manifests itself by a magnetic compensation point.

Derkachenko et al. [2] were the first to observe such effect in some $\mathrm{TbFe}_{1-x} \mathrm{Al}_{x} \mathrm{O}_{3}$ compounds. In $\mathrm{TbFeO}$, the $\mathrm{Tb}-\mathrm{Fe}$ interaction is ferromagnetic in character and no compensation temperature is observed. However, even a very small amount of Al substitute causes a rapid change in this interaction. The Tb-Fe coupling changes its sign, becoming antiferromagnetic, and a compensation point appears. However, those measurements have been done for the smallest amount of Al only. In the present work, we extend the investigation of $\mathrm{TbFe}_{1-x} \mathrm{Al}_{x} \mathrm{O}_{3}$ solid solutions to the whole range of $\mathrm{Al}$ concentration.

\section{EXPERIMENTAL RESULTS}

Eleven polycrystalline samples of nominal concentration $x=0,0.03,0.06,0.10,0.20,0.40,0.50,0.60,0.70,0.80,1$ were prepared by the usual sintering method [3] and their structure was examine by X-ray method. The agreement factor $R$ did not exceed $2.5 \%$ for all samples, which confirms a monophase and well-defined structure (Pbnm) for all $x$.

Magnetic susceptibility of the samples was measured using Faraday's method on a Cahn RG automatic electrobalance in magnetic field $\mathrm{H} \approx 0.045 \mathrm{~T}$ and temperature range $-3-273 \mathrm{~K}$. The measurement procedure was analogical to that of Ref. [3].

In obtained results, three ranges of $\mathrm{Al}$ concentration $(x)$ can be distinguished:

1. 0-0.20 - no anomalies are observed on the coinciding (ZFC) and (FC) curves; except for the lowest temperatures,

2. 0.40-0.70 - below $\sim 180-200 \mathrm{~K}$, the (ZFC) and (FC) curves do not coincide, at $-35 \mathrm{~K}$ a singularity is observed for both curves,

3. 0.80-1 - both ( $\mathrm{ZFC}$ and $\mathrm{FC}$ ) curves do not show any anomalies and coincide for all temperatures.

To verify a nature of mentioned above singularity additional neutron diffraction investigations were undertaken for three compounds of $x=0.5,0.6$ and 0.7 . Powder neutron diffraction patterns were collected for several temperatures within the range of 1.8-45 $\mathrm{K}$ (both below and above $\sim 35 \mathrm{~K}$ ) - neither crystal nor magnetic structure changes are observed. 


\section{DISCUSSION}

The comparison of the $\chi(\mathrm{T})$ curves of $\mathrm{TbFeO}_{3}$ and $\mathrm{TbFe}_{0.97} \mathrm{Al}_{0.03} \mathrm{O}_{3}$ shows a significant reduction of the magnetic susceptibility value for the smallest amounts of Al. This fact points to a rapid weakness of the ferromagnetic Tb-Fe coupling. Further dilution of the Fe sublattice may cause a change of this coupling sign and lead to compensation point appearance.

A compensation point has already been registered for terbium-orthoferrite with $x=0.055$, using a single crystal sample [2]. In our investigations no singularities have been observed directly for $\chi(T)$ curves in the range of $x \leq 0.20$. However, if one takes the difference between $[\chi(T)]_{x}$ and $[\chi(T)]_{x=1}$, an anomaly can be noticed for $x \geq 0.06$, which is interpreted by us as a symptom of the compensation phenomenon. The above mentioned circumstances permit us to claim that the sign change of the Tb-Fe interaction takes place in the range $0.03 \leq x \leq 0.055$.

For higher Al concentrations, $(0.40 \leq x \leq 0.70)$, the compensation manifests itself (in our opinion) directly as a sharp kink on $\chi(\mathrm{T})$ (for both $\mathrm{ZFC}$ and FC runs) (Fig.1). We consider that singularity to be the compensation point, since any (crystal or magnetic) structure transition has been excluded by neutron diffraction analysis.

The dependence of the obtained compensation temperatures on $\mathrm{Al}$ content is shown in Fig.2.

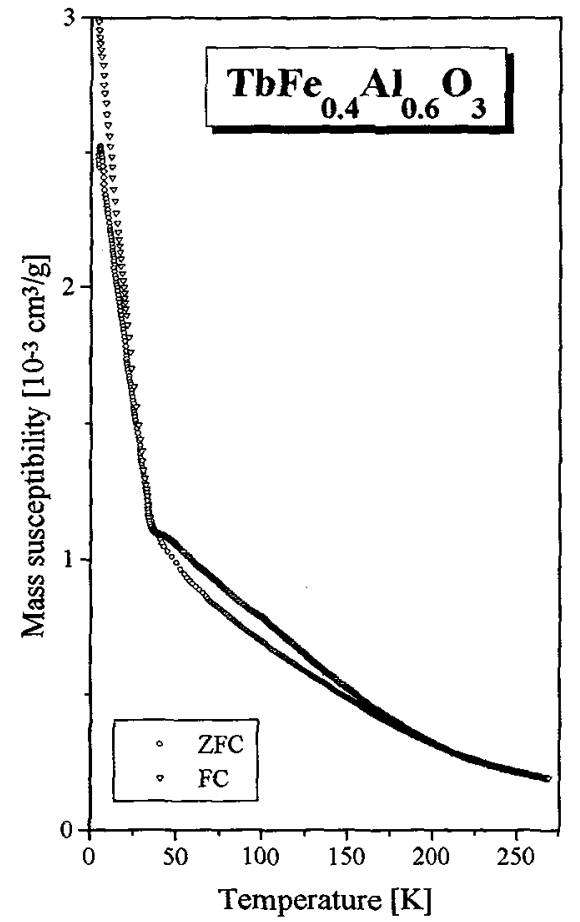

Figure 1: Temperature dependence of magnetic susceptibility at $\mathrm{H}=0.45 \mathrm{kOe}$.

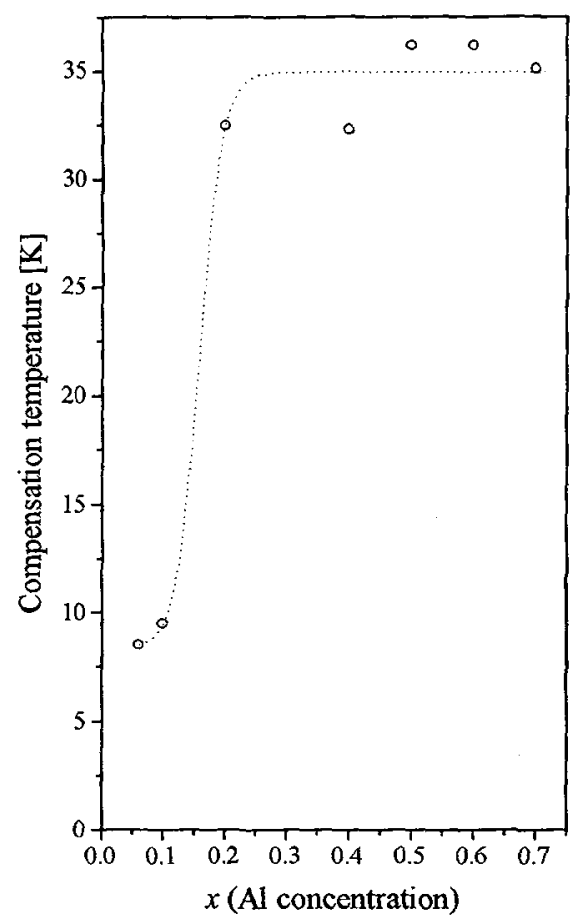

Figure 2: The compensation temperature as a function of the $\mathrm{Al}$ concentration.

\section{Acknowledgements}

This work was partly supported by research grant No. 2-P302-118-06 from the State Committee for Scientific Research.

\section{Reference}

[1] Bostrem I.G., Sinicin E.V., Fiz. Tverdogo Tela (USSR) 33 (1991) 462-465.

[2] Derkachenko V.N., Zvezdin A.K., Kadomtseva A.M., Kovtun N.M., Lukina M.M and Mukhin A.A., Phys. Stat. Sol. (a) 84 (1984) 215-222.

[3] Bombik A., Leśniewska B., Pacyna A.W., J. Mag. Magn. Mat. 146 (1995) 42-46. 